\title{
Research Article \\ Research on Public Transit Network Hierarchy Based on Residential Transit Trip Distance
}

\author{
Gao Jian, Zhao Peng, Zhuge Chengxiang, and Zhang Hui
}

School of Traffic and Transportation, Beijing Jiaotong University, Beijing 100044, China

Correspondence should be addressed to Zhao Peng, 11114242@bjtu.edu.cn

Received 9 May 2012; Revised 9 July 2012; Accepted 26 July 2012

Academic Editor: Wuhong Wang

Copyright (C) 2012 Gao Jian et al. This is an open access article distributed under the Creative Commons Attribution License, which permits unrestricted use, distribution, and reproduction in any medium, provided the original work is properly cited.

To the problem of being lack of transit network hierarchy theory, a research on public transit network hierarchy optimization based on residential transit trip distance is conducted. Firstly, the hierarchy standard of transit network is given, in addition, both simulating electron cloud model and Rayleigh distribution model are used to fit the residential transit trip distance. Secondly, from the view of balance between supply and demand, the hierarchy step of transit network based on residential transit trip distance is proposed. Then, models of transit's supply turnover and demand turnover are developed. Finally, the method and models are applied into transit network optimization of Baoding, Hebei, China.

\section{Introduction}

Giving priority to the development of public transportation system plays a pivotal role in alleviating urban traffic congestion. Recently, with the fast expansion of the city size, the public transit lines get much larger and higher density. Many researchers attended to ensure each transit lines' function by hierarchical public transit network, and then a public transportation service system with clear hierarchy can be established, which can guide residence's travel behavior scientifically.

The notion of multilevel transit network planning has been widely acknowledged and adopted. Carrese and Gori [1] considered three-route hierarchies; the other studies focus on specific linkages such as feeder routes for a rail network; Bagloee and Ceder [2] divided the transit network into three degrees: mass route, feeder route and local route, and the method to determine hierarchy of a route is studied; Van Goeverden and van Nes [3] describes how the public transport system consists of different network levels; van Nes [4] proposed multilevel network optimization for public transport networks and he [5] also 
conducted research on multiclass urban transit network design; Salzborn [6] and Knoppers and Muller [7] also optimized the transit network based on hierarchy concept. Jian and Gang [8], Wei et al. [9] proposed the multilevel transit network planning concept during planning the public transit network; Fangqiang [10] conducted transit network optimization based on transit network hierarchy from the view of coupling residential trip with transit network; Kuah and Perl [11] presented a mathematical model for feeder-bus network-design problem. They solved this model by a heuristic method called savings heuristic. Shrivastava and O'Mahony [12] designed feeders for one of heavy rail suburban service stations and coordinated schedules with the aid of genetic algorithm. Guillot [13] and Higgins [14] also conducted research on the bus network of a city was coordinated with the rail network. Chien et al. [15] applied genetic algorithm to design the feeders of a real network and its delay at intersections. Mohaymany and Gholami [16] used multiple modes with various capacities and performances in the feeder network design based on the minimization of user, operator, and social costs. Verma and Dhingra $[17,18]$ designed feeders of rail transit and presented a synchronized scheduling for rail and its feeders. Shrivastav and Dhingra [19] applied their heuristic feeder route generation algorithm to make a feeder network.

Although many researchers have conducted study related to hierarchy of public transit network, most of them did not propose any quantitative methods to calculate reasonable length for each hierarchical public transit network. In addition, travel behavior is widely studied and many transportation problems are solved based on it [20], so this paper attempts to put forward a hierarchy of public transit network which is applicable to certain urban development patterns and suitable for urban residents who travel by public transit in view of the fact that, at the moment, there is no such hierarchy based on the different demands of ridership and trip distance (resulting in the lack of arteries and local route lines).

\section{Analysis on Transit Trip Distance Distribution}

\subsection{Method of Determining Hierarchy of the Transit Network}

A rational public transit network should include different hierarchy types which operate with different standards. This paper categorizes public transit lines into 3 types: (1) mass route, which is the skeleton of the network; (2) feeder route, which operates inside of the district; (3) Local route, which serves as support facility to the mass route.

Hierarchy of a route and station spacing has been considered as the criteria of determining the network: (1) All the rail transit lines are regarded as mass routes, (2) public transit lines might qualify as mass routes when they are located along the express way or arterial road and the bus-stop spacing is longer than $800 \mathrm{~m}$, (3) feeder route is the transit line that is located along the arterial road or subarterial road and the bus-stop spacing is between $500 \mathrm{~m}$ and $800 \mathrm{~m}$, and (4) the remaining unclassified lines are all counted as local routes. There are still certain points of disagreements on the above criteria. Herein, we set up following provisions to pave the ways for later modeling.

(1) One public transit line alone may cover different hierarchy types of route, as shown in Figure 1. In such case, if the trip covers different types, the transfer time is 0.

(2) Lines passing the same section of the road are well considered to make sure that they all belong to the same hierarchy type. 


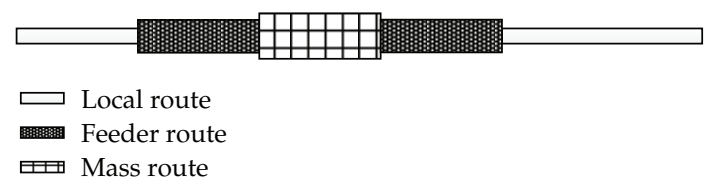

Figure 1: Sketch of transit network hierarchy types.

Table 1: Parameters and coefficients of determination in simulating electron cloud model and Rayleigh distribution model.

\begin{tabular}{lcccc}
\hline \multirow{2}{*}{ Cities } & \multicolumn{2}{c}{ Electron cloud model } & \multicolumn{2}{c}{ Rayleigh distribution model } \\
& $a_{0}$ & $R^{2}$ & $\lambda$ & $R^{2}$ \\
\hline Shenyang & 4.9 & 0.969 & 0.0312 & 0.962 \\
Suzhou & 7.7 & 0.977 & 0.0130 & 0.982 \\
Qinhuangdao & 6.2 & 0.974 & 0.0196 & 0.979 \\
Bengbu & 5.7 & 0.965 & 0.0233 & 0.965 \\
Yinchuan & 6.9 & 0.960 & 0.0160 & 0.953 \\
Wujiang & 5.1 & 0.977 & 0.0283 & 0.970 \\
Changshu & 4.6 & 0.963 & 0.0343 & 0.958 \\
Suzhou & 4.7 & 0.982 & 0.0341 & 0.979 \\
Huaibei & 4.5 & 0.980 & 0.0366 & 0.978 \\
Changde & 5.4 & 0.980 & 0.0258 & 0.977 \\
Chaozhou & 5.2 & 0.990 & 0.0275 & 0.985 \\
Weifang & 5.2 & 0.989 & 0.0270 & 0.983 \\
$R^{2}$ & Mean value $=0.976$ & Mean value $=0.973$ \\
& Standard deviation $=0.009$ & \multicolumn{2}{c}{ Standard deviation $=0.010$} \\
\hline
\end{tabular}

\subsection{Analysis on Transit Trip Distance Distribution}

The simulation of electron cloud model and Rayleigh distribution model are both widely used in the research of trip distance [16-18]. The applicability of these two models in the study of transit trip distance has been explored in this paper. Please refer to $[17,18]$ for more detailed introduction of these two models. Data from twelve different cities (Shenyang, Suzhou, Qinhuangdao, Bengbu, Yinchuan, Wujiang, Changshu, Suzhou, Huaibei, Changde, Chaozhou, and Weifang) have been used to compare the above models.

Cumulative probability distribution function of the electron cloud model and Rayleigh distribution model are: $F(s)=1-\left(2\left(s / a_{0}\right)^{2}+2\left(s / a_{0}\right)+1\right) e^{-2\left(s / a_{0}\right)}$ and $F(s) 1-e^{\left(-0.5 / s^{2}\right)}$ respectively. Table 1 shows the values of parameters involved. The comparative analysis has been conducted in terms of precision in simulating and ability in interpreting:

(1) Precision in simulating: values of fitting function $R^{2}$ indicate that both models have very high fitting precision. However, after analyzing the mean values and standard deviations of $R^{2}$, the electron cloud model turned out to be a better approach.

(2) Ability in interpreting: $\lambda$ derived from the Rayleigh distribution model has no actual meaning, whereas $\alpha_{0}$ derived from electron cloud model means the average trip distance. Consequently, the latter performs better.

Given those two aspects, electron cloud model is more feasible for the theory stated here. 


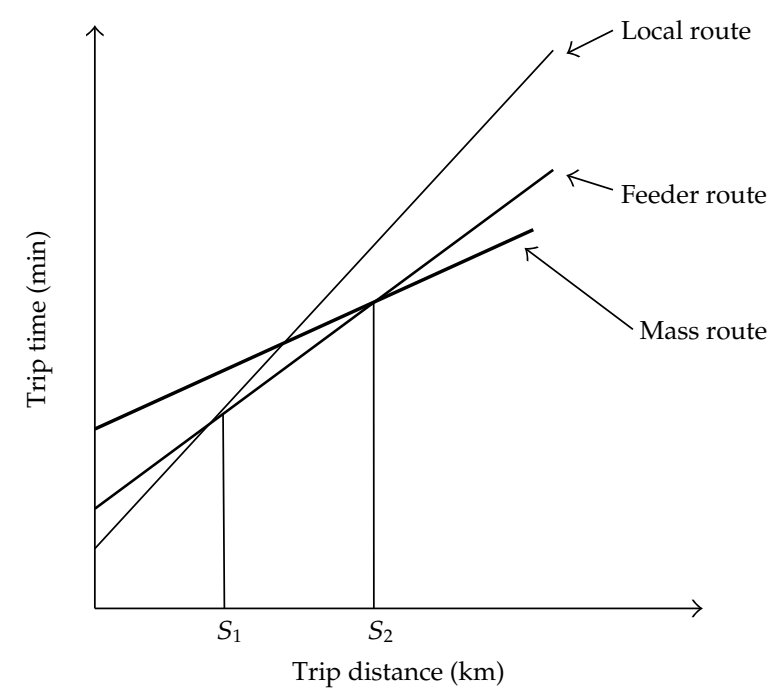

Figure 2: The relationship between transit trip distance and trip time.

\section{Hierarchy of Transit Network Based on Balance between Supply and Demand}

\subsection{Concepts of Transit Hierarchy Planning}

The optimized allocation of transit network is to study the balance between supply and demand of the public transit system at the macroscopic level. The typical quantitative indicators are the transit's supply turnover and demand turnover. Attempts have been made to balance the supply and demand through rational categorizing the network.

\subsection{Analysis on Demand Turnover of Different Hierarchy Types}

\subsubsection{Optimal Trip Distance of Public Transit Lines in Different Types of Route}

Different public transit lines have varies missions and desired length of passengers' trips (see Figure 2). When the trip distance is less than $S_{1}$, local routes are more favorable. When it is between $S_{1}$ and $S_{2}$, feeder routes are better options. If the distance is longer than $S_{2}$, mass routes have obvious superiority. The problem of how to figure out preferential trip distance can thus be converted to the calculation of critical values $S_{1}$ and $S_{2}$, which can easily be obtained by equations: $T_{\text {local }}=T_{\text {feeder }}, T_{\text {feeder }}=T_{\text {mass }}$ ( $T$ stands for the minimum trip time). Hence, the following model mainly focused on the trip time.

\section{(I) Explanation and Hypothesis of the Model}

(1) Here, we assume that the layout of the system is rational, and typical square grid with proportional spacing was used, as shown in Figure 3.

(2) The transfer of passengers follows a strict order: local route to feeder to mass, or the other way around. 
(3) Layout of every type of route is arranged in order of hierarchy (from mass to local), one encompasses another, that is, $r_{3}>r_{2}>r_{1}, r_{3}, r_{2}$, and $r_{1}$ are spaces between mass routes (including express way and arterial road), feeders, and local routes.

(4) Average transfer time equals waiting time, exclusive of time spent on walking to the transfer station. $T_{\alpha \beta \text { _transfer }}$ represents the average transfer time. $(\alpha, \beta=1,2,3$ which stands for local, feeder, and mass, resp.).

(II) Modeling Procedure

Definition of the parameters involved are as follow:

$i=1,2,3$-local, feeder, mass;

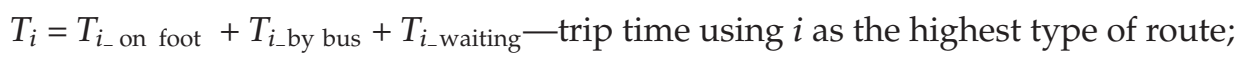

$T_{i_{-} \text {on foot }}$-total walking time from starting point to the station and from the station to destination;

$V_{\text {on foot }}$-walking velocity;

$T_{i_{\text {b by bus }}}$ - time spent on the vehicle;

$T_{i_{-} \text {waiting }}$-transfer time at transfer station;

A-area of the city;

$L_{k}$-length of each type of route; $k=1,2,3$-local, feeder, mass;

$\rho_{k}=L_{k} / \mathrm{A}$-road network density;

$r_{k}$-space between routes of the same hierarchy type;

$1 / r_{k}=\rho_{k} / 2, r_{k}=2 A / L_{k}$;

it is assumed that $d_{k}$ equals $r_{k} / 2$;

$\eta_{i-n}$-coefficient of determination on transfer;

$n$-number of transfers;

if there is no transfer during the trip, $\eta_{i_{-} n}=0$, otherwise, $\eta_{i_{-} n}=T_{\alpha \beta \text { transfer; }}$;

$\overline{n_{i}}$ - average transfer time;

$V_{i}$-velocity of the vehicle on type of route $i$;

$P_{\text {trip }}$-trip distance.

(1) Minimum Trip Time Using Local Routes as the Highest Type of Route. Figures 4 and 5 demonstrate the shortest path by this means. Span of travelling on foot is $\left(0,2 d_{1}\right]$ (see Figure 3), to simplify the model, mean value of $d_{1}$ is used.

The minimum trip time is

$$
\begin{gathered}
T_{1}=T_{1_{-} \text {on foot }}+T_{1_{-} \text {by bus }}+T_{1_{-} \text {waiting }} \\
T_{1_{-} \text {on foot }}=\frac{d_{1}}{V_{\text {on foot }}} \\
T_{1_{- \text {by bus }}}=\frac{\left(P_{\text {trip }}-d_{1}\right)}{V_{1}}, \\
T_{1_{-} \text {waiting }}=\eta_{1 \_1}+\eta_{1 \_2}+\cdots+\eta_{1_{n}}=\bar{\eta}_{1} .
\end{gathered}
$$


(2) Minimum Trip Time Using Feeder as the Highest Type of Route. Figures 6 and 7 show the shortest path by this means. We assume that in this case, local routes only play a supplementary role, accordingly, the mean value of $d_{1}$ is still used as the travelling on foot, because the span of travelling by local routes is $\left(0,2 d_{2}\right]$ (see Figure 3). To simplify the model, mean value of $d_{2}$ is used.

The minimum trip time is

$$
\begin{aligned}
& T_{2}=T_{2 \text { - on foot }}+T_{2 \text {-by bus }}+T_{2 \text {-waiting }} \\
& T_{2-\text { on foot }}=\frac{d_{1}}{V_{\text {on foot }}}, \\
& T_{2 \text { by bus }}=T_{1_{\text {_out }}}+T_{2 \text { _on the way }}+T_{1 \_ \text {back }}=\frac{d_{2}}{V_{1}}+\frac{\left(P_{\text {trip }}-d_{1}-d_{2}\right)}{V_{2}} \\
& T_{2 \text {-waiting }}=\eta_{2 \_1}+\eta_{2 \_2}+\cdots+\eta_{2_{n}}=\bar{\eta}_{2}
\end{aligned}
$$

where $T_{1_{-} \text {out }}$ is the time spent from starting point to feeder via local route. $T_{2 \text { - on the way }}$ is time spent on the feeder. $T_{1-\text { back }}$ is time spent from feeder to destination via local route. $T_{1_{-} \text {out }}=$ $T_{1 \_ \text {back. }}$.

(3) Minimum Trip Time Using Mass Routes as the Highest Type of Route. Figures 8 and 9 show the shortest path by this means. Assume that mass route is the major route taken, feeder and local route act as the supplement, can be obtained in the same way, the mean value of $d_{1}$ and $d_{2}$ are still used as the travelling on foot and traveling by local route, respectively. The span of travelling by feeder route is $\left(0,2 d_{3}-2 d_{1}\right.$ ] (see Figure 3$)$. To simplify the model, mean value of $d_{3}-d_{1}$ is used.

The minimum trip time is

$$
\begin{aligned}
& T_{3}=T_{3 \text { - on foot }}+T_{3 \text {-by bus }}+T_{3 \text {-waiting }} \\
& T_{3_{-} \text {on foot }}=\frac{d_{1}}{V_{\text {on foot }}}, \\
& T_{3 \text { by bus }}=T_{1_{\text {_out }}}+T_{2 \text { _out }}+T_{3_{-} \text {on the way }}+T_{2 \text { _back }}+T_{1_{\text {_back }}} \\
& =\frac{d_{2}}{V_{1}}+\frac{\left(d_{3}-d_{1}\right)}{V_{2}}+\frac{\left[P_{\text {trip }}-\left(d_{2}+d_{3}\right)\right]}{V_{3}}, \\
& T_{3-\text { waiting }}=\eta_{3-1}+\eta_{3 \_2}+\cdots+\eta_{3_{n}}=\bar{\eta}_{3} \text {, }
\end{aligned}
$$

where $T_{1 \text {-out }}$ is the time spent from starting point to feeder via local route, $T_{2 \text {-out }}$ is the time spent from local route to mass route via feeder. $T_{3-}$ on the way is the time spent on the mass route. $T_{2 \text { back }}$ is the time spent from mass route to local route via feeder. $T_{1_{-} \text {back }}$ is time spent from feeder to destination via local route. $T_{1_{\text {_out }}}=T_{1_{-} \text {back }}, T_{2_{-} \text {out }}=T_{2_{-} \text {back }}$. 


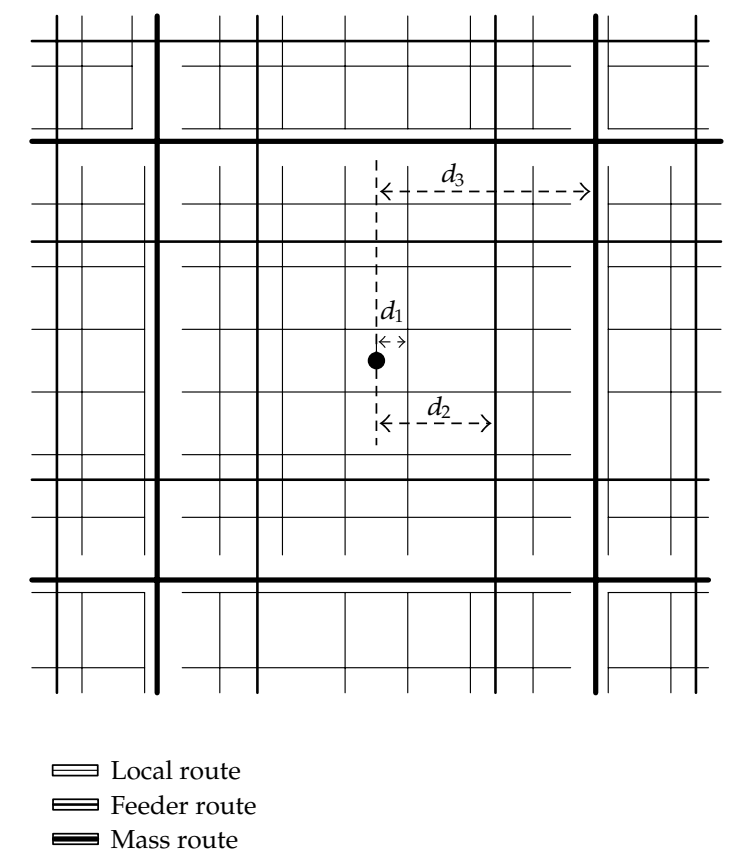

Figure 3: Sketch of transit network.

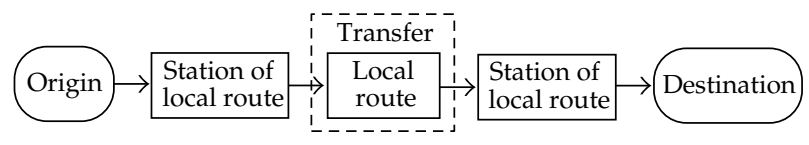

Figure 4: The shortest path using local routes as the highest type of route.

(4) Calculation of Optimal Distance on Every Type of Route. Set $T_{1}$ is equal to $T_{2}, T_{2}$, equal to $T_{3}$, Then:

$$
\begin{aligned}
& S_{1}=\left(d_{1}+d_{2}\right)+\frac{V_{2} \cdot V_{1}}{V_{2}-V_{1}} \cdot\left(\overline{\eta_{2}}-\overline{\eta_{1}}\right), \\
& S_{2}=\left(d_{2}+d_{3}\right)+\frac{V_{3} \cdot V_{2}}{V_{3}-V_{2}} \cdot\left(\overline{\eta_{3}}-\overline{\eta_{2}}\right) .
\end{aligned}
$$

\subsubsection{Analysis on Demand Turnover of Different Types of Route}

\section{(I) Proportion of Passengers on Each Highest Type of Route}

The proportion of passengers who take local route, feeder, and mass route as their highest type of route is as follow.

Local Route: $w_{1}=\int_{0}^{s_{1}} f(s) d s$; Feeder Route: $w_{2}=\int_{s_{1}}^{s_{2}} f(s) d s$; Mass Route: $w_{3}=$ $\int_{s_{2}}^{+\infty} f(s) d s$. 


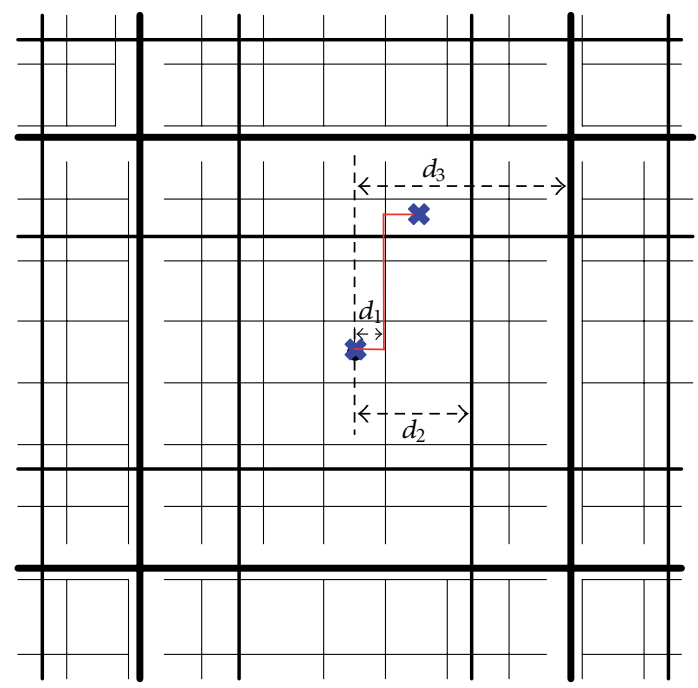

* Origin/destination — Travel route

Figure 5: The sketch map of shortest path using local routes as the highest type of route.

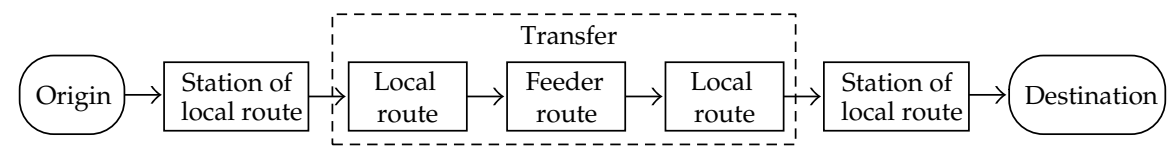

Figure 6: The shortest path using feeder as the highest type of route.

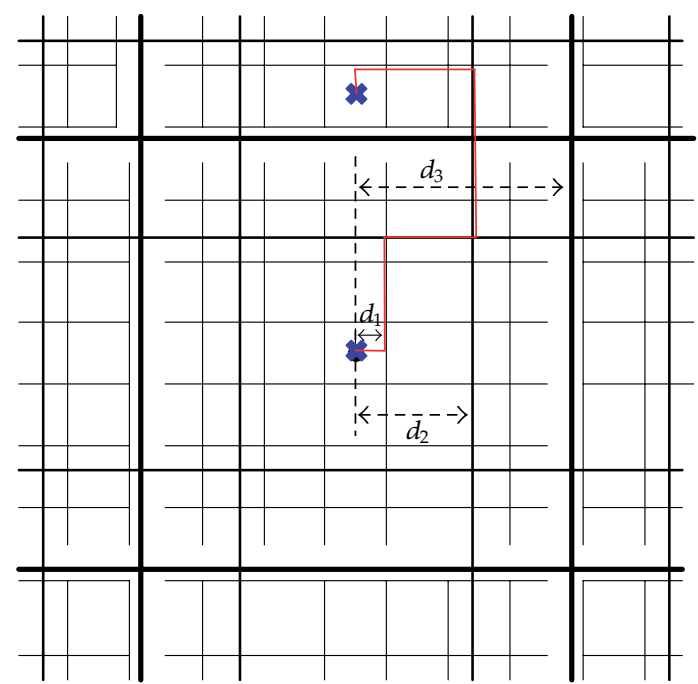

* Origin/destination _ Travel route

Figure 7: The sketch map of shortest path using feeder as the highest type of route. 


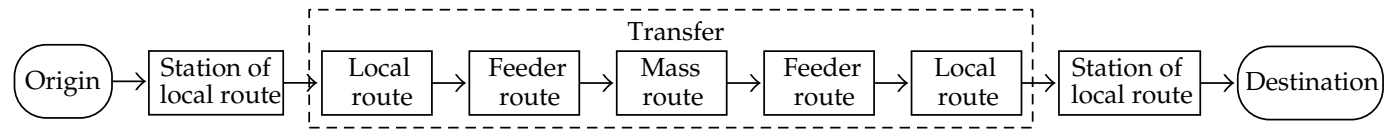

Figure 8: The shortest path using mass route as the highest type of route.

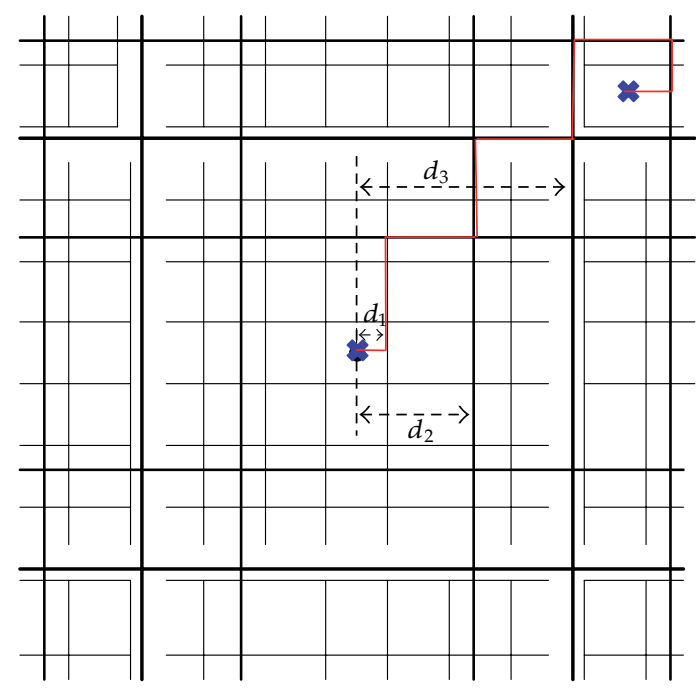

* Origin/destination

— Travel route

Figure 9: The sketch map of shortest path using mass route as the highest type of route.

\section{(II) Average Trip Distance of Passengers on Each Highest Type of Route}

The average trip distance of passengers who take local route, feeder, and mass route as their highest type of route is as follow.

Local Route: $\overline{S_{1}}=\int_{0}^{s_{1}} f(s) s d s / \int_{0}^{s_{1}} f(s) d s$; Feeder Route: $\overline{S_{2}}=\int_{s_{1}}^{s_{2}} f(s) s d s / \int_{s_{1}}^{s_{2}} f(s) d s$; Mass Route: $\overline{S_{3}}=\int_{s_{2}}^{+\infty} f(s) s d s / \int_{s_{2}}^{+\infty} f(s) d s$.

\section{(III) Demand Turnover on Each Type of Route}

Referring to previous studies [21,22] on this issue, calculation method of demand turnover on each type of route is proposed as follows.

(1) $Z_{i}$ is defined as the turnover completed by unit passenger using $i$ as the highest type of route, $z_{i j}$ the component of $Z_{i}$ completed on route type $j(j \leq i)$. Thus, $Z_{i}=$ $\sum_{j=1}^{i} z_{i j}$

(2) $z_{i j}$ is affected by the choice unit passenger make on each trip, which makes the solution complicated and time-consuming. Therefore, certain simplification has been made. We assume that the turnover on route type inferior to $i$ can be seen as the product between the number of passengers who take $i$ as the highest type of route and average trip distance made by passengers who take $i-1$ as the highest 
type. In this case, $z_{i j}$ approximately is equal to $Z_{i}$ minus the product. The rest such as turnover completed on route type inferior to $i-1$ can be done in the same manner.

Hence, demand turnover on each type of route can be calculated as follows.

(1) Turnover completed on the local routes only

$$
Z_{1}=z_{11}=W \cdot w_{1} \cdot \int_{0}^{s_{1}} f(s) s d s
$$

where, $W$ is the total number of trip time.

(2) Turnover completed on the feeder routes only

$$
\begin{gathered}
Z_{2}=W \cdot w_{2} \cdot \int_{s_{1}}^{s_{2}} f(s) s d s=z_{21}+z_{22} \\
z_{21}=\overline{S_{1}} \cdot W \cdot w_{2} \\
z_{22}=Z_{2}-z_{21}=W \cdot w_{2} \cdot\left(\int_{s_{1}}^{s_{2}} f(s) s d s-\overline{S_{1}}\right) .
\end{gathered}
$$

(3) Turnover completed on the mass routes only

$$
\begin{gathered}
Z_{3}=W \cdot w_{3} \cdot \int_{s_{2}}^{+\infty} f(s) s d s=z_{31}+z_{32}+z_{33} \\
z_{31}=\overline{S_{1}} \cdot W \cdot w_{3} \\
z_{31}+z_{32}=\overline{S_{2}} \cdot W \cdot w_{3} \Longrightarrow z_{32}=W \cdot w_{3} \cdot\left(\overline{S_{2}}-\overline{S_{1}}\right), \\
z_{33}=Z_{3}-\left(z_{31}+z_{32}\right)=W \cdot w_{3} \cdot\left(\int_{s_{2}}^{+\infty} f(s) s d s-\overline{S_{2}}\right) .
\end{gathered}
$$

(4) Demand turnover on each type of route: demand turnover on local route, feeder; and mass route is represented as $Z Z_{1}, Z Z_{2}$, and $Z Z_{3}$ and total turnover $Z_{\text {total. }}$. The relationships between $Z_{\text {total }}, Z Z_{i}, Z_{1}$, and $z_{i j}$ are shown in Table 2 .

\subsection{Analysis on Supply Turnover of Different Hierarchy Types}

Supply capacity of each type of route demands departure frequency, operating hours, type of vehicle, and load factor. Assume that supply turnover is $G Z_{i}$.

Departure Frequency: the average frequency on each type of route $f_{i}=60 / \overline{\mu_{i}}$ is used, where $\overline{\mu_{i}}$ is the average departure interval (min). 
Table 2: The relationship among different classes (types) of turnover.

\begin{tabular}{lcccc}
\hline Hierarchy type & Local route & Feeder route & Mass route & $\Sigma$ \\
\hline Local route & $Z_{11}$ & - & - & $Z_{1}$ \\
Feeder route & $Z_{21}$ & $Z_{22}$ & - & $Z_{2}$ \\
Mass route & $Z_{31}$ & $Z_{32}$ & $Z_{33}$ & $Z_{3}$ \\
$\Sigma$ & $Z_{1}$ & $Z_{2}$ & $Z Z_{3}$ & $Z_{\text {total }}$ \\
\hline
\end{tabular}

Type of Vehicle: passenger flow varies on different types of route. Therefore, different types of vehicle are equipped accordingly. It is assumed that rated passenger load of vehicles on each type of route is $E_{i}$.

Load Factor: load factor $\phi_{i}$ is an important factor to indicate the comfort of the vehicle.

Then, supply turnover of each type of route is

$$
G Z_{i}=E_{i} \cdot T_{i \text { run }} \cdot f_{i} \cdot \varphi_{i} \cdot G L_{i}
$$

where $T_{i_{-} \text {run }}$ is the operating hours in one day, $G L_{i}$ is the length of each type or route.

\subsection{Analysis on Balance between Demand and Supply on Each Type of Route}

Based on the analysis in Sections 3.2 and 3.3, here, we assume that supply turnover equal demand turnover, then, $G Z_{i}=Z Z_{I}$ (see Table 2), the desired length of each type of route is.

$$
G L_{i}=\frac{1}{E_{i} \cdot \varphi_{i} \cdot T_{i_{-} \text {run }}} \cdot Z Z_{i}
$$

\section{A Case Study: Baoding}

Located in Heibei Province, Baoding has $100 \mathrm{~km}^{2}$ lands for construction and the population had reached 1.06 million by 2009. The length of express way, mass route, feeder, and local route are $82.6 \mathrm{~km}, 116.3 \mathrm{~km}, 74.1 \mathrm{~km}$, and $222.7 \mathrm{~km}$, respectively. The total length is $495.7 \mathrm{~km}$. The application's process and results are as follows.

\section{(1) Values of Parameters Involved}

Based on analysis of the public transit survey of Baoding, the values of parameters involved (the detail explanation of the parameters can be found in Section 3.3) are calculated and the results are as follows:

(1) $E=\left[E_{1}, E_{2}, E_{3}\right]=[72,98,98]$;

(2) $\bar{\mu}=\overline{\mu_{1}}, \overline{\mu_{2}}, \overline{\mu_{3}}=[10,8,6]$;

(3) $\bar{\eta}=\left[\overline{\eta_{1}}, \overline{\eta_{2}}, \overline{\eta_{3}}\right]=[5,9,12]$;

(4) $V=\left[V_{1}, V_{2}, V_{3}\right]=[15,20,25]$; 
Table 3: Road length of each transit hierarchy in baoding.

\begin{tabular}{lcccc}
\hline Different situations & local $(\mathrm{km})$ & $\begin{array}{c}\text { Types of route } \\
\text { feeder }(\mathrm{km})\end{array}$ & mass $(\mathrm{km})$ & Total length $(\mathrm{km})$ \\
\hline$\varepsilon=0.9$ & 1493 & 1229 & 347 & 3069 \\
$\varepsilon=0.95$ & 1576 & 1297 & 366 & 3239 \\
$\varepsilon=1.05$ & 1741 & 1434 & 405 & 3580 \\
$\varepsilon=1.10$ & 1824 & 1502 & 424 & 3751 \\
Actual supply & 399 & 645 & 690 & 1734 \\
\hline
\end{tabular}

(5) $\varphi_{1}=\varphi_{2}=\varphi_{3}=0.9$;

(6) $T_{1_{\text {_run }}}=T_{2_{\text {_run }}}=T_{3_{\text {_run }}}=16 \mathrm{~h}$.

\section{(2) Important Outcomes}

Trip distance is simulated with electron cloud model; the probability density function is $f(s)=\left(4 s^{2} /(5.4)^{3}\right) e^{-2 s / 5.4}$, with $R^{2}=0.995$. The model's precision in simulating is high enough to be applied.

There exists a dynamic balance between supply of the transit network and demand of passengers. Dynamic balance coefficient is assumed as $\varepsilon\left(\varepsilon_{i}=G Z_{i} / Z Z_{i}\right)$. If $\varepsilon \leq 0.9$, supply is inadequate, if $0.9<\varepsilon \leq 0.95$ or $1.05<\varepsilon \leq 1.10$, supply just matches demand, if $0.95<\varepsilon \leq 1.05$, supply matches demand perfectly, if $\varepsilon>1.10$, supply is sufficient.

Table 3 shows the demand (obtained by calculation) and supply (actual data) undervaries situations. Comparative analysis indicates that the public transit network in Baoding has the following problems.

(1) Total length is relatively short. Currently, the actual supply length of Baoding's transit line is $1734 \mathrm{~km}$, in order to reach the level $\varepsilon=0.9$ (the supply length should be $3069 \mathrm{~km}$ ), nearly $1300 \mathrm{~km}$ length of transit line should be added. The main reason why the total length is so short is because the lack of local routes whose main function is to expand service range of the transit network and to make walking distance as short as possible. The actual supply length of local route is only $399 \mathrm{~km}$, which is far from the demand of level (supply length of local route should be $1493 \mathrm{~km}$ ), therefore, local routes should be relatively longer and have higher densities.

(2) The length of mass routes is relatively long. Currently, the actual supply length of mass routes is $690 \mathrm{~km}$, which is much longer (nearly $340 \mathrm{~km}$ longer) than the requirement of level $\varepsilon=0.9$ (the supply length can be $347 \mathrm{~km}$ ). Large-scale distribution centers and functional areas are connected by mass routes which require high-speed transport. However, currently the size of Baoding city is at moderate level, and trip distance of residents is generally short, the length of existing mass routes seems a bit redundant.

To solve these problems, the idea of hierarchy planning is proposed as follows.

(1) Construction of local routes should be strengthened in order to shorten the distance between bus station and origin or destination, consequently shorten the walking distance which facilitates bus travel. 
(2) Increase or decrease the grade of the transit routes to achieve rational route configuration. For example, alter mass route to feeder route or feeder to local route.

(3) According to the above two ideas, a specific measure is put out as an example to meet the demand of level $\varepsilon=0.9$ : (a) decrease the some mass routes' grade, thus, there will $350 \mathrm{~km}$ mass route will be changed into feeder routes, the length of feeder routes will be about $1000 \mathrm{~km}$; (b) add another $1000 \mathrm{~km}$ of local routes. By the above two ways, the hierarch of Baoding's public transit will be much reasonable and level $\varepsilon=0.9$ can be reached.

\section{Conclusion}

A hierarchy planning toward public transit network is developed based on the distribution of passengers' trip distance. Main achievements are concluded as follows. (1) Trip distance is simulated with electron cloud model and Rayleigh distribution model, comparative analysis shows that the former has better precision in simulating and ability in interpreting. (2) A model for optimal trip distance of each hierarchy type of routes is proposed based on features of passengers in the public transit system; (3) A method of macroscopic calculation on hierarchy planning is developed, which is based on turnover balance between supply and demand. The above achievements have enriched the theory of hierarchy configuration of public transit network, and provide a feasible approach to transit network planning.

\section{Acknowledgment}

The authors would like to thank for financial support by the national science and technology support projects, under the Contract no. 2009BAG12A10-9.

\section{References}

[1] S. Carrese and S. Gori, “An Urban bus network design procedure," Applied Optimization, vol. 64, pp. 177-196, 2002.

[2] S. A. Bagloee and A. Ceder, "Transit-network design methodology for actual-size road networks," Transportation Research Part B, vol. 45, pp. 1787-1804, 2011.

[3] C. D. van Goeverden and R. van Nes, "Hierarchy in public transport networks: the case of Amsterdam," in Proceedings of the 11th World Conference on Transport Research, 2007.

[4] R. Van Nes, "Multilevel network optimization for public transport networks," Transportation Research Record, vol. 1799, pp. 50-57, 2002.

[5] R. Van Nes, "Multiuser-class urban transit network design," Transportation Research Record, vol. 1835, pp. 25-33, 2003.

[6] F. J. M. Salzborn, "Scheduling bus systems with interchanges," Transportation Science, vol. 14, no. 3, pp. 211-231, 1980.

[7] P. Knoppers and T. Muller, "Optimized transfer opportunities in public transport," Transportation Science, vol. 29, no. 1, pp. 101-105, 1995.

[8] L. jian and H. Gang, "Level planning method of bus-route network and its application," Urban Transport of China, vol. 2, no. 4, pp. 34-37, 2004.

[9] W. Wei, Y. Xinmiao, and C. Xuewu, Urban Trnasit Planning Method and Management Techonology, Science press, Beijing, China, 2002.

[10] L. Fangqiang, The Application of Coupling Models between Inhabitant Trip Distribution and Public Transport Network, Southeast University, Nanjing, China, 2010.

[11] G. K. Kuah and J. Perl, "The feeder-bus network-design problem," Journal of the Operational Research Society, vol. 40, no. 8, pp. 751-767, 1989. 
[12] P. Shrivastava and M. O'Mahony, "A model for development of optimized feeder routes and coordinated schedules-A genetic algorithms approach," Transport Policy, vol. 13, no. 5, pp. 413-425, 2006.

[13] E. Guillot, "Bus transit interface with light rail transit in Western Canada," Transportation Research Part A, vol. 18, no. 3, pp. 231-241, 1984.

[14] T. J. Higgins, "Coordinating buses and rapid rail in the San Francisco Bay Area: the case of Bay Area rapid transit," Transportation, vol. 10, no. 4, pp. 357-371, 1981.

[15] S. I. Chien, L. N. Spasovic, S. S. Elefsiniotis, and R. S. Chhonkar, "Evaluation of feeder bus systems with probabilistic time-varying demands and nonadditive time costs," Transportation Research Record, no. 1760 , pp. 47-55, 2001.

[16] A. S. Mohaymany and A. Gholami, "Multimodal feeder network design problem: ant colony optimization approach," Journal of Transportation Engineering, vol. 136, no. 4, pp. 323-331, 2010.

[17] A. Verma and S. L. Dhingra, "Feeder bus routes generation within integrated mass transit planning framework," Journal of Transportation Engineering, vol. 131, no. 11, pp. 822-834, 2005.

[18] A. Verma and S. L. Dhingra, "Developing integrated schedules for urban rail and feeder bus operation," Journal of Urban Planning and Development, vol. 132, no. 3, pp. 138-146, 2006.

[19] P. Shrivastav and S. L. Dhingra, "Development of feeder routes for Suburban railway stations using heuristic approach," Journal of Transportation Engineering, vol. 127, no. 4, pp. 334-341, 2001.

[20] W. Wang, W. Zhang, H. Guo, H. Bubb, and K. Ikeuchi, "A safety-based behavioural approaching model with various driving characteristics," Transportation Research Part C-Emerging Technologies, vol. 19, no. 6, pp. 1202-1214, 2011.

[21] S. Fei, Research on Grade Proportion and Layout Method of Urban Road, Southeast University, Nanjing, China, 2006.

[22] Z. Zhuping, Road Network Gradation Optimization Model According To Traffic Demand, Southeast University, Nanjing, China, 2009. 


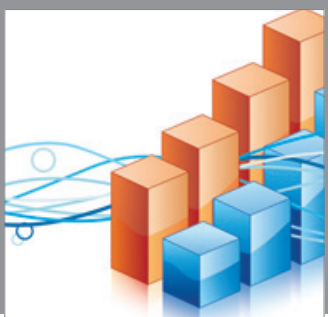

Advances in

Operations Research

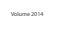

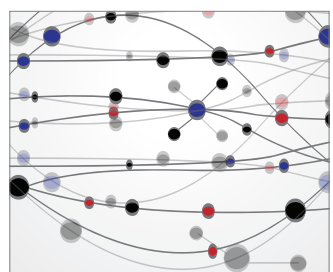

\section{The Scientific} World Journal
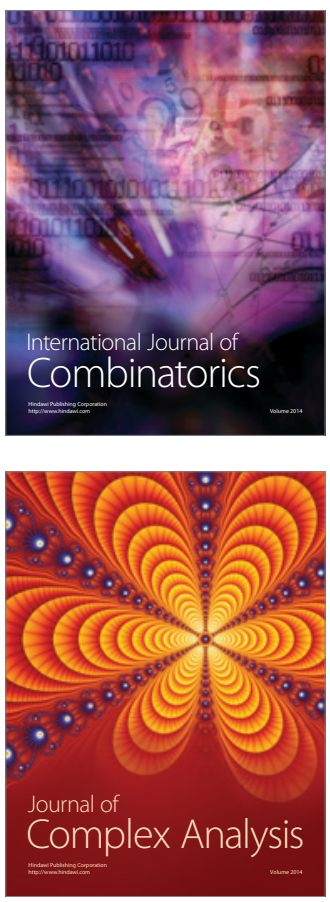

International Journal of

Mathematics and

Mathematical

Sciences
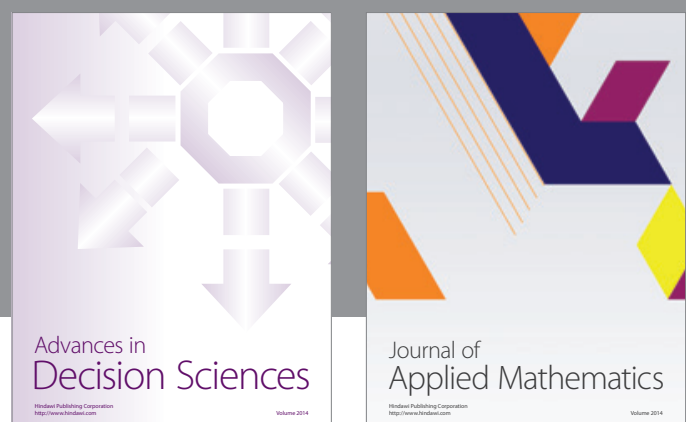

Journal of

Applied Mathematics
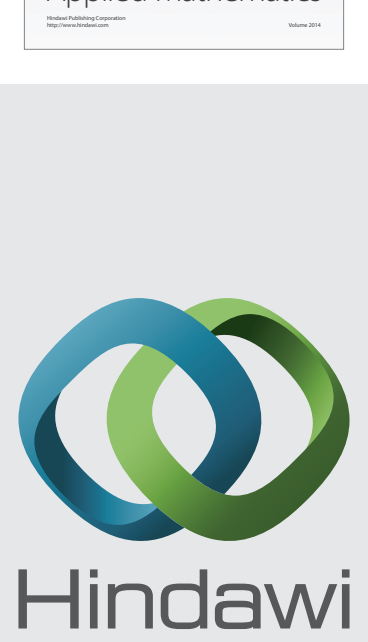

Submit your manuscripts at http://www.hindawi.com
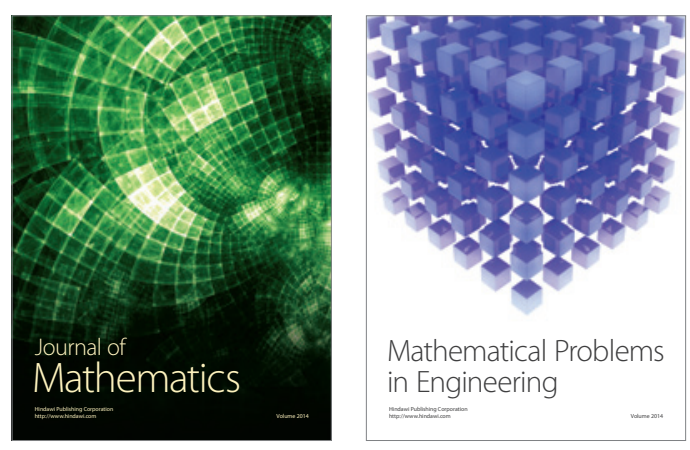

Mathematical Problems in Engineering
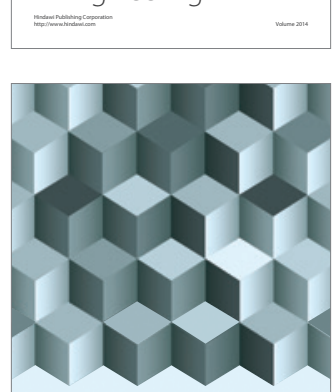

Journal of

Function Spaces
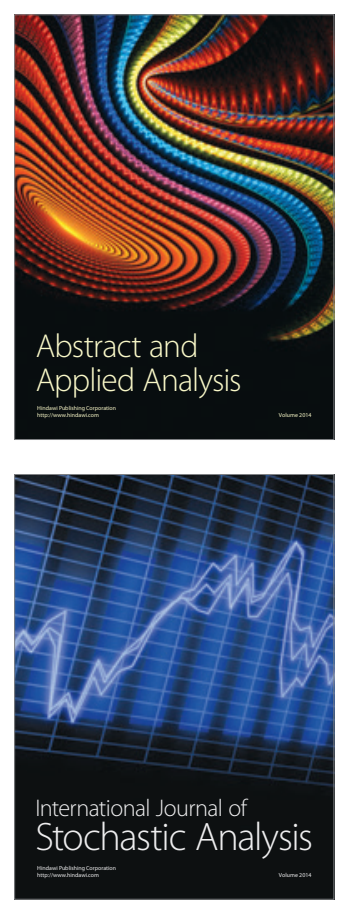

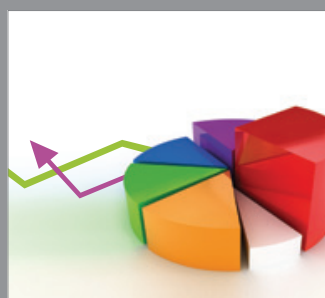

ournal of

Probability and Statistics

Promensencen
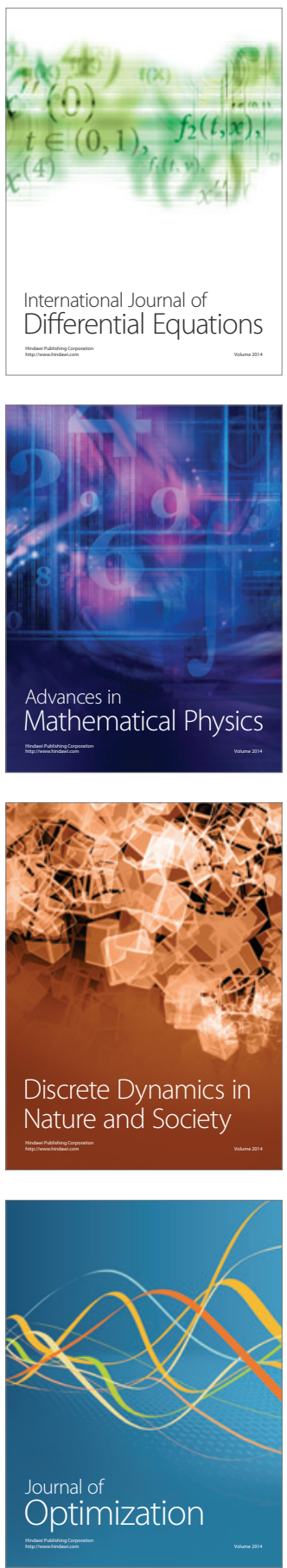